\title{
COVID-19 Pandemic: lessons learnt and the way forward
}

\author{
Gathsaurie Neelika Malavige* \\ AICBU, Department of Immunology and Molecular Medicine, Faculty of Medical Sciences, \\ University of Sri Jayewardenepura, Sri Lanka
}

Date Received: 11-11-2021 Date Accepted: 17-12-2021

\begin{abstract}
Although the scientific community had been predicting and preparing for a pandemic for the last 10 years, many policy makers did not envision that a virus could cause such devastation to human life, economies and to the social structure. COVID-19 has taught us many bitter lessons and while moving forward it is important to understand that this current pandemic is yet to end. However, COVID-19 is unlikely to be the last pandemic that we face, Due to certain human activities such as urbanization, deforestation, increased human and animal interactions and climate change, we will see more pandemics emerging in the coming years. Preparedness and anticipation of such an event is the only way forward.
\end{abstract}

\section{Introduction}

The SARS-CoV-2 virus emerged two years ago and spread like wildfire across continents, overwhelming the most developed health care systems and killing thousands each day. Although the official figures report approximately 5 million deaths for the two years since the beginning of the COVID19 pandemic (Medicine, 2021), the actual figures have been estimated as 17 million deaths (Economist, 2021). Not only did millions of people lose their lives, but millions also lost their livelihoods. Currently many countries are struggling to revive their economies, deal with the increase burden of mental health problems and social problems that occurred to due to this pandemic (Mian et al., 2021). However, the pandemic is not over, and it is still causing havoc in many lower income countries, which have vaccinated less than $5 \%$ of their population, while the countries that have managed to vaccinate a large proportion of adults are finally experiencing a reduction in mortality rates (Ritchie H., 2021).

While this pandemic might have come as a surprise for many, scientists working on infectious diseases, zoonosis and large international funding bodies, have been expecting this for many years (Morse et al., 2006, Monto, 2006). Large funding bodies such as the National Institute of Health, USA, anticipating an imminent pandemic, established the Centres for Research on Emerging Infectious Diseases Research (CRIED) ((NIAID), 2021), comprising of ten research centers spanning across the globe, which includes our laboratory (A2CARES, 2021). Despite this anticipation, even the most developed countries with pandemic preparedness plans in place, were severely affected. However, the developed countries were able to develop different their vaccines, run the clinical trials, immunize their population at a lightning speed, while many lower-income and lower middle income countries in the African and Asian region are not being able to do so due to the unavailability of vaccines.

*Correspondence: neelika@sjp.ac.lk

Tel: +94772443193

(C) University of Sri Jayewardenepura 


\section{Ending the current pandemic}

The initial strategy of many countries was to eliminate the virus through strict lockdowns, mass scale testing to identify each infected person and then strict and extended quarantines, this was soon proven to be futile with the emergence of SARS-CoV-2 variants such as delta (Phillips, 2021). Clinical trials which began early in the epidemic were able to identify drugs that did work and did not, and thereby enabling physicians to better manage their patients and reducing mortality rates (Group et al., 2021). Many countries developed vaccines and there are currently eight vaccines for prevention of COVID-19, which have received WHO emergency use listing. The inactivated vaccine developed by Bharat Biotech, India is the most recent vaccine added to this list. Although vaccines were found to be less effective in preventing infection, all vaccines were shown to be very effective in preventing severe disease and death. Therefore, many countries are scrambling to vaccinate their population as fast as possible in order to resume usual economical and educational activities.

Despite the everyone trying to end this pandemic with vaccination, better treatment methods and control health measures involving the general public, this has been a difficult task due to many very wellorganized campaigns against these efforts. While many individuals developed innovative drugs or repurposed traditional and Western drugs for treatment of COVID-19 in a scientific manner, there were many more who capitalized on the misery faced by the public and marketed and recommended various unproven 'cures'. Along with these 'cures' many others marketed 'immune boosters' that claimed to prevent contracting the virus. These campaigns, carried out in Sri Lanka and many other countries in the world, had a significant impact on the vaccine campaign and on efforts to end the pandemic. The rise in 'infodemic' along with the rise in the number of cases and deaths due to COVID-19, was the main hindrance to achieving control of the pandemic and alleviating public fear (Banerjee and Meena, 2021). Apart from social media contributing to the 'infodemic', both social media and mainstream media significantly contributed to the stigma associated with COVID-19, in countries such as Sri Lanka.

As it has dawned upon as that COVID is 'here to stay'(Ahsan et al., 2021, Phillips, 2021), it is crucial that a collaborative effort from all stake holders is required to end this pandemic, while the virus will continue to live on as an endemic pathogen.

\section{Endemic COVID-19 and living with the virus}

Due to the huge loss in life and the morbidity that occurred due to COVID-19 (Economist, 2021), many find it difficult to comprehend that this virus will be with us forever. Therefore, it is important to realise what it means when we transition from a pandemic to an endemic state. A pandemic state is when a pathogen causes a large outbreak involving many continents in the world. When a pathogen becomes endemic, it does not cause outbreaks but infects a few individuals in the community throughout the year (Health, 2021). Therefore, a few individuals in the community will continue to be infected by the SARS$\mathrm{CoV}-2$, while some are likely to require hospital admission, as we see with many other endemic infections such as dengue (Malavige et al., 2021). However, when a pathogen is in an endemic state it can give rise to large outbreaks, which might be seasonal, as we see with dengue and influenza (Malavige et al., 2021) or we might see changes in the virus, which might give rise to massive outbreaks as experienced with dengue during year 2017 (Wijewickrama et al., 2018). In order to prevent large outbreaks from occurring and in order to be alerted for emergence of different variants, it is crucial that we have long term plans to carry out active surveillance for emerging variants through widespread sequencing of the SAR-CoV-2 viruses in a systematic manner. It is also important to continue to carry out active surveillance of all individuals who develop COVID-19 like symptoms to monitor changes in the virus that may give rise to variants with higher transmissibility or with the ability to evade immunity induced by vaccines. 


\section{Developing science, technology and infrastructure to face the next pandemic}

With our species encroaching on the land of other species, clearing their habitat, and increased encounters with them, more 'spill-over' events, where animal viruses spilling over to infect humans is likely to occur at an increasing frequency in the future (Redding et al., 2019, Temmam et al., 2019). Therefore, we should be on continuous alert for such events and emergence of new pandemics. In this COVID-19 pandemic, the speed at which these vaccines were developed, and rolled out showed how much, us, the Homo sapiens have advanced in this world, were we are currently able to develop so many different vaccines and carry out clinical trials with such a short time. This achievement was only possible because of the unprecedented corporation between all stakeholders such as the scientists who develop vaccines, researchers who carry out clinical trials, funding bodies, ethics review committees and most importantly, the people of a country, all who were working towards a common goal. Due to an increase in human animal interaction and global travel, we will see more 'spill-over' pathogens rapidly spreading around the globe in future. The question is: is Sri Lanka ready? We will keep on depending on 'developed' countries to give us vaccines, at exorbitant prices or can we develop our own? While many have a romantic notion of Sri Lanka developing vaccines, laying the foundations stone now, is crucial to make this dream a reality.

\section{References}

(NIAID), N. I. O. A. A. I. D, 2021. Centers for Research in Emerging Infectious Diseases Network National Institute of Allergy and Infectious Diseases (NIAID) https:/creid-network.org/ Accessed 4th Novermber 2021

A2CARES. 2021. Asian-American Centers for Arbovirus Research and Enhanced Survillence (A2CARES) Centers of Research in Emerging Infectious Diseases (CREID) https://www.a2cares.com/ Accessed 4th Novermber 2021

Ahsan, H., Arif, A., Ansari, S. \& Khan, F. H. 2021. The emergence of Covid-19: evolution from endemic to pandemic. J Immunoassay Immunochem, 1-11.

Banerjee, D. \& Meena, K. S. 2021. COVID-19 as an "Infodemic" in Public Health: Critical Role of the Social Media. Front Public Health, 9, 610623.

Economist, T. 2021. The pandemic's true death toll. The Economist. https://www.economist.com/graphic-detail/coronavirus-excess-deaths-estimates Accessed 4th November 2021

Group, R. C., Horby, P., Lim, W. S., Emberson, J. R., Mafham, M., Bell, J. L., Linsell, L., Staplin, N., Brightling, C., Ustianowski, A., Elmahi, E., Prudon, B., Green, C., Felton, T., Chadwick, D., Rege, K., Fegan, C., Chappell, L. C., Faust, S. N., Jaki, T., Jeffery, K., Montgomery, A., Rowan, K., Juszczak, E., Baillie, J. K., Haynes, R. \& Landray, M. J. 2021. Dexamethasone in Hospitalized Patients with Covid19. $N$ Engl J Med, 384, 693-704.

Health, C. U. M. S. O. P. 2021. Epidemic, Endemic, Pandemic: What are the Differences? Columbia University Mailman School of Public Health. https://www.publichealth.columbia.edu/public-health-now/news/epidemic-endemicpandemic-what-are-differences Accessed 4th Novermber 2021

Malavige, G. N., Jeewandra, C., Ghouse, A., Somathilake, G. \& Tissera, H. 2021. Changing epidemiology of dengue in Sri Lanka-Challenges for the future. PLoS Negl Trop Dis, 15, e0009624.

*Correspondence: neelika@sjp.ac.lk

Tel: +94772443193

(C) University of Sri Jayewardenepura 
Medicine, J. H. U. A. 2021. Coronavrus Resource Centre. John Hopkins University. https://coronavirus.jhu.edu/ Accessed 28th June 2021

Mian, A., Al-Asad, S. \& Khan, S. 2021. Mental health burden of COVID-19. Fam Pract, 38, 195197.

Monto, A. S. 2006. Vaccines and antiviral drugs in pandemic preparedness. Emerg Infect Dis, 12, 55-60.

Morse, S. S., Garwin, R. L. \& Olsiewski, P. J. 2006. Public health. Next flu pandemic: what to do until the vaccine arrives? Science, 314, 929.

Phillips, N. 2021. The coronavirus is here to stay - here's what that means. Nature, 590, 382-384.

Redding, D. W., Atkinson, P. M., Cunningham, A. A., Lo Iacono, G., Moses, L. M., Wood, J. L. N. \& Jones, K. E. 2019. Impacts of environmental and socio-economic factors on emergence and epidemic potential of Ebola in Africa. Nat Commun, 10, 4531.

Ritchie H., O.-O. E., Beltekian D., Mathieu E., Hasell J., MacDonald B., Giattino C., Appel C., Lucas Rodes-Guirao, Rose M. 2021. Coronavirus Pandemic (COVID-19). OurWorldInData.org.

Temmam, S., Chretein, D., Bigot, T., Dufour, E., Petres, S., Desquesnes, M., Devillers, E., Dumarest, M., Yousfi, L., Jittapalapong, S., Karnchanabanthoeng, A., Chaisiri, K., Gangnieur, L., Cosson, J. F., Vayssier-Taussat, M., Morand, S., Moutailler, S. \& Eloit, M. 2019. Monitoring Silent Spillovers Before Emergence: A Pilot Study at the Tick/Human Interface in Thailand. Front Microbiol, 10, 2315.

Wijewickrama, A., Fernando, S., Jayerathne, G. S. B., Perera, P. A., Abeynaike, S. A., Gomes, L., Jeewandra, C., Tippalagama, R., Dilani, D., Rajendran, A., Abeysekere, R., Goonawardhane, S., De Silva, A. D. \& Malavige, G. N. 2018. Emergence of a Dengue virus serotype 2 causing the largest ever dengue epidemic in Sri Lanka. bioRxiv, 329318. 